\title{
Anti-money Laundering Awareness and Acceptance among the Bank Customers of Nepal
}

Aabha Joshi ${ }^{1}$, Ajay Kumar Shah ${ }^{2 *}$
Received: 18 August, 2020

Revised: 19 October, 2020

Accepted: 08 November, 2020

Published: 15 December, 2020
How to cite this paper:

Joshi, A., \& Shah, A.K. (2020). Anti-money laundering awareness and acceptance among the bank customers of Nepal. Quest Journal of Management and Social Sciences, 2(2), 337-347.

Copyright (C) 2020 by authors and Quest Journal of Management and Social Sciences.

This work is licensed under a Creative Commons Attribution-Non Commercial-No Derivatives 4.0 International License. https://creativecommons.org/ licenses/by-nc-nd/4.0/

\begin{abstract}
Background: Money laundering is a process of converting illegal money into legal money. This process is considered a challenging phenomenon for the financial system. To stop this exploitation of the financial system, anti-money laundering (AML) regimes are formulated. However, the general public acceptance is crucial to make the framework viable. Public awareness of Anti-money Laundering (AML) related factors helps people enforce the AML regimes properly.
\end{abstract}

Objective: The paper aims to examine the relationship between awareness of AML related factors and acceptance of AML regimes. Along with that, the study accesses the level of awareness and level of acceptance among bank clients about AML factors and AML regimes respectively.

Methods: Based on descriptive and inferential research designs, the study made use of primary data collected through a structured questionnaire surveyed on 168 bank customers who are of 18 years and above, using a convenience sampling technique. Descriptive analysis is used to access the level of awareness and acceptance, whereas the relationship between awareness and acceptance is examined through correlation and regression analysis.

Results: Bank customers are moderately aware of money laundering (ML) and terrorism financing (TF), and anti-money laundering (AML) along with Know Your Customer (KYC). However, they are somewhat and slightly aware of AML investigation agency and AML legislation respectively. Similarly, they have a slight acceptance attitude towards all AML regimes. There is a significantly positive relationship between awareness of AML related factors and acceptance for AML regimes.

Conclusions: Bank customers of Nepal have a comparatively higher awareness of ML, TF, AML and KYC than that of AML legislation and AML investigating agency. However, they have a similar acceptance attitude towards all three AML regimes. Acceptance for AML regimes can be increased by enhancing the awareness of AML related factors among the bank customers. The study, therefore, recommends the concerned authority like FIU-Nepal and NRB to undertake public awareness campaigns in related areas.

Implication: Study findings can be useful to policymakers and concerned authorities to formulate positive national policies sensitive to AML.

Keywords: Awareness, Acceptance, Money Laundering, Anti-money laundering, Know Your Customer

JEL Classification: E41, E51 


\section{Introduction}

Money laundering, also ML, is the process of sanitizing assets generated by criminal activity or illegal origins into legitimate money. If these assets or money are used to finance terrorist activity then it becomes terrorism financing or TF. Therefore, it is critical to have a comprehensive understanding of ML to completely understand TF (Mukhtar, 2018). These two phenomena differ in various ways; however, they exploit the same vulnerabilities in financial systems. To save the financial system from being a victim of ML, AML regimes and provisions came into existence. The AML regimes are the policies and measures implemented by concerned authority with the purpose to spot, discourage, and to prevent the ill use of banks for illegal activities. Basel Committee on Banking Supervision has delivered regimes concerning comprehensive management of risks associated to ML and TF are customer identification, customer verification, and monitoring and reporting of suspicious transactions (Financial Information Unit - Nepal, 2018). The AML regimes direct banks to strictly follow KYC requirements to identify and verify customers well, to monitor, and to report suspicious and large volume transactions.

ML has been recognized as a contemporary and challenging phenomenon for the global financial system (Demetis, 2010). Since, United Nations Office on Drugs and Crime (2017) mark that up to 800 billion to 2 trillion dollars, representing 2-5\% of global GDP, is the estimated amount of money laundered worldwide each year. The lack of enforcement law capacity, an unregulated banking system, and lack of internationally accepted ML provisions combine to create a haven for easy incorporation of unlawful proceeds into the mainstream economy (Joyce, 2002). Thus, it is crucial to implement strong AML regimes. However, doubt over Nepal's ability to implement viable AML regimes has been proven right in an assessment by Asia Pacific Group on ML which found substantial insufficiencies in the AML infrastructure and legislation of Nepal. Also, mark that Nepal does not fully attend any of the 49 standards set by FATF, a global AML watchdog (Know Your Country, n. d.). Mainly, not on EU White list equivalent jurisdictions, scored low in Corruption Index, the average score in World Governance Indicators, and the average score in Failed States Index put Nepal in danger to ML and raises doubts over Nepal's ability to implement viable AML regimes.

The AML is not the responsibility shouldered by the government or bank alone, the general public has equal responsibility. The consumers can help banks to eliminate the potential clients who pose a serious threat to the banks with their unaccounted money by disclosing their true information to banks while opening the bank account, updating KYC in time. This will make it difficult for money launderers and terrorists by closing the possible loopholes of identity fraud (Viritha and Mariappan, 2016). In short, customers simply can help by accepting the AML regimes imposed on them. But crucial thing is that they must be aware of the impact and importance of different facts related to AML to accept the AML regimes.

Gerstein and Hervieux-Payette (2013) recommended that the opinion of creating public awareness on the nature and scope of ML is a necessary step to implement strong AML regimes. Financial Intelligence Unit - Republic of Mauritius (2006) and Viritha and Mariappan (2016) state that there is a weak but significant relationship between awareness of AML and acceptance of AML regime in the context of the Republic of Mauritius and India respectively. However, to the best of our knowledge, no such research was conducted in Nepal to test the awareness and acceptance of bank customers. It is, therefore, necessary to examine (i) what type of relationship does the awareness of AML factors and acceptance for AML regimes portray in context of Nepal? (ii) what level of awareness does the bank customer of Nepal have on AML related factors? and (iii) what level of acceptance does the bank customer of Nepal have toward the AML regimes? Concerning these questions, this study mainly aims to examine the relationship between awareness of AML factors (ML and TF, AML and KYC, AML legislation, and AML investigation agency) and acceptance for AML regimes (information disclosure, 
updating $\mathrm{KYC}$ and transaction reporting). Along with that, the study accesses the level of awareness and level of acceptance of AML factors and AML regimes respectively.

As the study focuses on the analysis of AML awareness and acceptance of Nepalese bank customers, the outcome of this study makes an enormous significancefor the agencies concerned for AML, policymakers, and banks operating in Nepal. It is to formulate positive national policies on the framework that is applicable and sensitive to AML regulations in the banking industry in Nepal.

This study is organized into five different sections. The second section reviews the available literature. The third section describes the methodology. The fourth section presents and analyzes the data collected. Section five provides conclusions of the study.

\section{Review of Literature}

Financial institutions are required to implement various practices to prevent assets laundering by putting effective AML/CFT policies into place. The directive requires these policies and procedures to include Customer Due Diligence (CDD) or customers to be identified i.e. KYC (Financial Information Unit - Nepal, 2009; European Banking Authority, 2018). In their study, Vaithilingam and Nair (2007) advocatean efficient legal framework with good corporate governance that lowers the expansion of ML activities and high-innovative capacity contributes to positively implement AML measures in developing countries. Subbotina (2009) analyzes theAML legislation created by the Russian regulator for the financial institutions to test banks' compliance with it, found that the financial institutions and banks were unable to comply with the AML regulation. Outcome further questions the unwillingness or inability of the financial institutions or banks to comply with the regulator's rules. This inability isa challenge for the global AML regime.

Further, Chaikin (2009) and Viritha, Mariappan, and Haq (2015) evaluate the effectiveness of a Suspicious Transaction Reporting (STR) system in Switzerland and India respectively. Swiss STR system is found to be questionable because of the lack of thoughtful reporting of suspicious transactions yet efficient as large amounts of money are automatically frozen under the mandatory reporting obligation. In India, results show that there is a significant increase in the STRs filed within the period of the study, however, STR in India has just started intently and it still has a long way to go before achieving tangible results. Ai and Jun (2009) critically examine the practice of customer Due Diligence (CDD) compliance in China in response to the international requirement set by the FATF. The finding shows that CDD in Chinese banks has been updated constantly since 2007 and from the legislation view, China has attained the international standard but on the practical operation they still have a lot of work to do. Naheem's (2018) review some of the challenges of the Chinese banking sector that are posed by international ML schemes and suggests applying a risk-based system of CDD to analyze all clients under four key areas: client behavior, transaction patterns, geographical risk, and third-party involvement. Demetriades (2016) critically evaluate evolution of CDD measures in Cyprus and UK highlights the potential weaknesses of current CDD by comparing it with old-fashioned CDD measures. And it concludes that due to the evolution of technology, CDD is more efficient than ever based on solid ground, however, the use of old-fashioned due diligence measures might provide a more adequate investigation for high-risk customers such as third parties, politically exposed persons, and international clients.

The Republic of Ghana (2016) encourages all stakeholders to take part in awareness creation and capacity building to fight against ML and TF. By making education and awareness of ML/TF a priority, they follow a two-fold renewed policy focus approach that would result in both effective administrative and criminal sanctions regime approach. Whereas, creating awareness among auditors to detect unlawful money is emphasized by the Organization for Economic Co-operation and Development (2019). Singh (2009) stated that a lack of awareness among the general people in India about the problem of money-laundering is an obstacle in having a proper AML regime. Poor and illiterate people 
of India do not trust banks. Rather they prefer the hawala system to avoid the lengthy paperwork required to complete a money transfer through a FI. Gerstein and Hervieux-Payette (2013) enforce the opinion that advancements in technology and public awareness is necessary to implement strong AML policies. Public's unawareness of the nature and scope of ML/TF is posing threats against AML/CTF regime in Canada. Also, suggested the government of Canada to access the level of public awareness on ML/TF and AML/ATF regime to get a shred of baseline evidence to be used in future evaluations and to measure the extent of public acceptance of the regime.

Financial Intelligence Unit - Republic of Mauritius (2006) conducted a questionnaire survey on the general public above 18 years of age to access the awareness of ML and perception on the areas of risk. The result favors raising awareness among all stakeholder groups concerning AML legislation and the role of the FIU would weaken the potential ML activities and the majority of responses came in the favor of generating awareness on the ML impact and AML regime. Viritha and Mariappan (2016) conclude that there is a low level of awareness regarding usage of banks as a channel for ML and TF activities, reporting function of the banks, AML/CFT legislation, and Financial Intelligence Unit (FIU)India and its functions. However, customers seemed to be aware of ML and customer identification requirements. The partakers exhibited being neutral towards the acceptance of the AML regime. Also, a significant but weak relationship was found between the level of awareness and acceptance.

Various research have been done in various countries regarding the status and effectiveness of the AML, regime, analysis of STR, the description of the ML techniques and related ML cases and many more. Very few researches have unveiled the customer side of the story of AML. Particularly in Nepal, very few researches has been done so far. To the best of our knowledge, no research was conducted to test the awareness and acceptance of bank customers in Nepal. This paper, therefore, explores what type of relationship does the awareness of AML factors and acceptance for AML regimes portrays in the context of Nepal. Along with that, it accesses the level of awareness and acceptance of the bank customers of Nepal on AML factors and AML regimes respectively.

\section{Research Method}

\section{Conceptual Framework}

The study employed a descriptive research design and inferential analysis to achieve the objective of exploring the relationship between awareness of AML factors and acceptance for AML regimes. The conceptual framework for the study is presented in Figure 1. Dependent variables measure the level of acceptance for AML regimes, which comprises of information disclosure, updating KYC, and transaction reporting. The regimes taken for the study are the Central Bank's directives on AML/CFT to financial institutions operating in Nepal. Independent variables measure the level of awareness of AML related factors which consider ML and TF, AML and KYC, AML Legislation, and AML investigating agency. The independent variables are extracted from Viritha and Mariappan (2016). However, the independent variables with interdependence are merged as one variable. To examine the relationship between awareness and acceptance, the null hypothesis had been formulated between each independent variable to each dependent variable.

Figure 1. Conceptual Framework

\begin{tabular}{||c|c|}
\hline \multicolumn{1}{|c|}{ Independent Variable } & Dependent Variable \\
\hline Level of Awareness & \multicolumn{1}{|c|}{$\begin{array}{c}\text { Level of Acceptance } \\
\text { ML and TF }\end{array}$} \\
AML and KYC & Information Disclosure \\
AML Legislation & Updating KYC \\
AML Investigation Agency & Transaction Reporting \\
\hline
\end{tabular}


Awareness of ML and TF is measured based on knowledge of basic ML/TF and its impact on the economy and banking sector. AML and KYC awareness is based on the understanding of the essence of $\mathrm{KYC} / \mathrm{AML}$ and the interrelationship between these two variables. AML Legislation awareness is measured on the basis of familiarity with the acts formulated to counter ML. AML Investigation Agency awareness is measured on the knowledge regarding agencies' responsibility to control ML and their functions. Acceptance of information disclosure is measured by customers' fondness to provide critical information like other bank account information, property information. Acceptance for KYC updating is measured based on their attitude towards the bank's action, for example if a costumer does not update KYC timely, the bank might suspend transactions or close the account. Transaction reporting acceptance is measured by fondness towards specious transaction reporting.

\section{Study Area, Population and Sample}

The population for the study was all the above 18 years old bank account holders of Nepal as (Kam, 2011) banks normally discourage young people under the age of 18 from opening an account independently. Mackey and Gass (2005) recommended that the minimum sample number for descriptive research is more than 100, thus, a structured questionnaire was distributed to the potential respondent and 168 responses were received resulting in around 68.5 percent response rate. A close-ended questionnaire was offered to restrict the response within the given alternative. Convenience Sampling Technique was used to track the respondents from a homogeneous population. An electronic survey method was conducted because the data were collected at the time of the COVID-19 pandemic and was based on self-administered questionnaires.

\section{Reliability of Data}

The reliability was tested through Cronbach Alpha Method to check the internal consistency of the constructs. Taber (2017) marks that Cronbach's alpha value of 0.7 or greateris the acceptance level of reliability and is considered to be good enough. Here, the reliability of all the variables is above 0.7 , thus, the variables are good enough to carry out the study.

Table 1. Coefficient of Cronbach's Alpha

\begin{tabular}{|c|c|c|}
\hline Variables & Cronbach's alpha & Remarks \\
\hline ML and TF & 0.881 & Good \\
\hline $\mathrm{AML}$ and $\mathrm{KYC}$ & 0.889 & Good \\
\hline AML legislation & 0.945 & Excellent \\
\hline AML investigation agency & 0.969 & Excellent \\
\hline Information disclosure & 0.805 & Good \\
\hline Updating KYC & 0.774 & Acceptable \\
\hline Transaction reporting & 0.778 & Acceptable \\
\hline
\end{tabular}

\section{Data Analysis}

The data was analyzed using various descriptive statistic tools such as percentage, mean, and standard deviation AML factors and its regimes to access the level of awareness and acceptance of bank customers regarding KYCs and anti ML. To inference, the relationship between the dependent and the independent variable correlation and regression analysis was employed. However, the conclusion is based on the outcome of the correlation analysis as this method is used to find a linear relationship between two variables. Regression, on the other hand, is used to inference the impact of one variable on another. 


\section{Data Analysis and Results}

\section{Descriptive Analysis}

This section of data analysis presents the simple description of respondents' profile, level of awareness and level of acceptance.

Table 2: Respondents Profile

\begin{tabular}{clcc}
\hline Category & \multicolumn{1}{c}{ Response Category } & Frequency & Percentage (\%) \\
\hline \multirow{3}{*}{ Gender } & Male & 95 & 56.5 \\
& Female & 73 & 43.5 \\
\cline { 2 - 4 } & Total & $\mathbf{1 6 8}$ & $\mathbf{1 0 0 . 0}$ \\
\hline \multirow{5}{*}{ Age group } & $18-24$ years & 47 & 28 \\
& $24-30$ year & 91 & 54.2 \\
& $30-36$ year & 16 & 9.5 \\
& 36 year or above & 14 & 8.3 \\
\cline { 2 - 4 } & Total & $\mathbf{1 6 8}$ & $\mathbf{1 0 0 . 0}$ \\
\hline \multirow{5}{*}{ Occupation } & Job Holder & 60 & 35.7 \\
& Self-employed & 19 & 11.3 \\
& Student & 88 & 52.4 \\
& Housemaker & 1 & 0.6 \\
\cline { 2 - 4 } & Total & $\mathbf{1 6 8}$ & $\mathbf{1 0 0 . 0}$ \\
\hline
\end{tabular}

The distribution of respondents according to gender shows that majority of respondents are male $(56.5 \%)$ followed by female respondents $(43.5 \%)$. Age group distribution indicates that the majority of respondents were of 24-30 years. The distribution of respondents according to occupation reveals that the majority of respondents are students, followed by job holders and housemaker.

Table 3: Descriptive Analysis of Level of Awareness

\begin{tabular}{lcc}
\hline \multicolumn{1}{c}{ Descriptive Analysis: Level of Awareness } & Mean & Standard Deviation \\
\hline ML and TF & 3.62 & 1.013 \\
AML and KYC & 3.81 & 1.061 \\
AML Legislation & 2.35 & 1.189 \\
AML Investigation Agency & 2.44 & 1.288 \\
\hline
\end{tabular}

The statements were rated from 1-5. (1= Not at all aware, $2=$ Slightly aware, $3=$ Somewhat aware, $4=$ Moderately aware, 5= Extremely aware)

Table 4: Descriptive Analysis of Level of Acceptance

\begin{tabular}{lcc}
\hline \multicolumn{1}{c}{ Descriptive Analysis: Level of Acceptance } & Mean & Standard Deviation \\
\hline Information Disclosure & 3.68 & 0.919 \\
Updating KYC & 3.60 & 1.010 \\
Transaction Reporting & 3.61 & 0.917 \\
\hline
\end{tabular}

The statements were rated from 1-5. (1= Unacceptable, $2=$ Slightly unacceptable, $3=$ Neutral, 4= Slightly acceptable, $5=$ Acceptable) 
Table 3 shows that the level of bank customers' awareness is good. Nepalese bank customers are highly aware of (i.e. mean awareness level of 3.6 out of 5) AML and KYC followed by the awareness of ML and TF (3.62), AML investigation agency (2.44) and AML legislation (2.35). Similarly, table 4 indicates descriptive analysis of the dependent variables to access the level of acceptance of AML regimes shows slightly acceptable in the scale for all three regimes. However, the acceptance for information disclosure is comparatively higher.

\section{Correlation Analysis}

The correlation analysis (presented in table 5) indicates that all four independent variables have a significant positive relationship with all three dependent variables at a significant level i.e. $(\alpha)=0.01$. Whereas the relationship between AML legislation and updating KYC is significant at a significant level at $(\alpha)=0.05$. Hence, this study finds that all the independent variables are highly correlated with each of the dependent variables. The highest correlation is observed between awareness of AML and $\mathrm{KYC}$ and acceptance for information disclosure.

Table 5. Correlation Analysis

\begin{tabular}{|c|c|c|c|c|c|c|}
\hline & $\mathrm{X} 2$ & $\mathrm{X} 3$ & $\mathrm{X} 4$ & Y1 & Y2 & Y3 \\
\hline \multirow[t]{2}{*}{$\mathrm{X} 1$} & $0.730 * *$ & $0.447 * *$ & $0.431 * *$ & $0.374 * *$ & $0.209 * *$ & $0.414 * *$ \\
\hline & 0.000 & 0.000 & 0.000 & 0.000 & 0.007 & 0.000 \\
\hline \multirow[t]{2}{*}{$\mathrm{X} 2$} & 1 & $0.382 * *$ & $0.384 * *$ & $0.474 * *$ & $0.326^{* *}$ & $0.422 * *$ \\
\hline & & 0.000 & 0.000 & 0.000 & 0.000 & 0.000 \\
\hline \multirow[t]{2}{*}{$\mathrm{X} 3$} & & 1 & $0.772 * *$ & $0.286 * *$ & $0.175^{*}$ & $0.263 * *$ \\
\hline & & & 0.000 & 0.000 & 0.023 & 0.001 \\
\hline \multirow[t]{2}{*}{$\mathrm{X} 4$} & & & 1 & $0.332 * *$ & $0.246 * *$ & $0.287 * *$ \\
\hline & & & & 0.000 & 0.001 & 0.000 \\
\hline \multirow[t]{2}{*}{ Y1 } & & & & 1 & $0.625 * *$ & $0.604 * *$ \\
\hline & & & & & 0.000 & 0.000 \\
\hline \multirow[t]{2}{*}{ Y2 } & & & & & 1 & $0.575 * *$ \\
\hline & & & & & & 0.000 \\
\hline
\end{tabular}

** Correlation is significant at the 0.01 level (2-tailed).

* Correlation is significant at the 0.05 level (2-tailed).

Here $X_{1}, X_{2}, X_{3}$ and $X_{4}$ represent the independent variables. They are symbolized for $X_{1}=M L$ and TF, $\mathrm{X}_{2}=\mathrm{AML}$ and $\mathrm{KYC}, \mathrm{X}_{3}=\mathrm{AML}$ Legislation and $\mathrm{X}_{4}=\mathrm{AML}$ Investigation Agency. In other hand, $\mathrm{Y}_{1}, \mathrm{Y}_{2}$ and $\mathrm{Y}_{3}$ are dependent variables representing $\mathrm{Y}_{1}=$ Information Disclosure, $\mathrm{Y}_{2}=$ Updating $\mathrm{KYC}$ and $\mathrm{Y}_{3}$ $=$ Transaction Reporting. 


\section{Regression Analysis}

Table 6: Regression Results of Information Disclosure

\begin{tabular}{lcccc}
\hline Dependent Variable: Information Disclosure & Beta & Tvalue & P-value & VIF \\
\hline ML and TF & 0.005 & 0.058 & 0.954 & 2.313 \\
AML and KYC & 0.350 & 4.042 & 0.000 & 2.167 \\
AML legislation & -0.010 & -0.117 & 0.907 & 2.575 \\
AML investigation agency & 0.131 & 1.703 & 0.091 & 2.542 \\
Constant & 2.031 & 8.164 & 0.000 & \\
R Square & 0.251 & & & \\
P Value & 0.000 & & & \\
F Value & 13.634 & & & \\
\hline
\end{tabular}

Table 7: Regression Results of Updating KYC

\begin{tabular}{lcccc}
\hline Dependent Variable: Updating KYC & Beta & Tvalue & P-value & VIF \\
\hline ML and TF & -0.103 & -0.934 & 0.352 & 2.313 \\
AML and KYC & 0.332 & 3.242 & 0.001 & 2.167 \\
AML legislation & -0.067 & -0.675 & 0.500 & 2.575 \\
AML investigation agency & 0.170 & 1.869 & 0.063 & 2.542 \\
Constant & 2.451 & 8.331 & 0.000 & \\
R Square & 0.131 & & & \\
P Value & 0.000 & & & \\
F Value & 6.168 & & & \\
\hline
\end{tabular}

Table 8: Regression Results of Transaction Reporting

\begin{tabular}{lcccc}
\hline Dependent Variable: Transaction Reporting & Beta & Tvalue & P-value & VIF \\
\hline ML and TF & 0.173 & 1.804 & 0.073 & 2.313 \\
AML and KYC & 0.207 & 2.342 & 0.020 & 2.167 \\
AML legislation & -0.002 & -0.022 & 0.982 & 2.575 \\
AML investigation agency & 0.081 & 1.033 & 0.303 & 2.542 \\
Constant & 2.005 & 7.875 & 0.000 & \\
R Square & 0.212 & & & \\
P Value & 0.000 & & & \\
F Value & 10.980 & & & \\
\hline
\end{tabular}

Regression results from all three tests (presented in Table 6,7 and 8) indicate that awareness of AML and $\mathrm{KYC}$ has a significant impact on the acceptance for information disclosure, update of $\mathrm{KYC}$ as well as transaction reporting. The R-square value of regression presented in Table 6 is 0.251 , which states that the independent variables explain the acceptance for information disclosure by $25.1 \%$ meaning it consists of many other factors as well that influence the acceptance for information disclosure. Similarly, the R-square observed in Table 7 is 0.131 , indicating that the independent variables explain the acceptance for updating KYC by $13.1 \%$. This outcome suggests that it consists of many other factors as well that influence the acceptance for updating KYC. Likewise, an R-square of 0.212 (in table 8) states that the independent variables explain the acceptance for transaction reporting by $21.2 \%$. 
It indicates several other factors are also responsible for accepting transaction reporting. In both results, awareness of ML and TF, AML legislation, and AML investigation agency does not impact the acceptance.The Variance Inflation Factor (VIF) in each variable is less than 10 so there is no multicollinearity. Similarly, the regression model fits the data in view of the F-value and significant level of 6.168 and 0.000 respectively. It identifies a positive linear relationship between awareness of AML factors and acceptance for information disclosure, updating $\mathrm{KYC}$ as well as transaction reporting.

\section{Discussion}

The findings of the study suggest that Nepalese bank customers are highly conscious of AML and $\mathrm{KYC}$. The reason behind higher awareness could be because the awareness resources on KYC/AML policies, role and responsibilities of bank customers in this regard are displayed on the website of the bank and/or in the form of poster and display boards, etc. At the time of KYC fill-up and account opening process, detailed information regarding AML/CFT is provided to the customer (Prabhu Bank Limited, 2019). Similarly, findings suggest that bank customer lacks the awareness of AML legislation. Less awareness of AML legislation could be because of the public's ignorant attitude toward the national law and rules as it frequently changes in Nepal. Also, in Nepal, citizens often lack an essential level of awareness of the contents of the law due to the inadequate 'civic education' (United Nations Development Programme Nepal, 2017).

Nepalese bank customers showed a similar acceptance attitude toward all three regimes of AML which is quite satisfactory with the scale being slightly acceptable.Comparing this outcome with Viritha and Mariappan (2016), it shows that the acceptance level of AML regime in Nepal is higher than in India. The Indian public has a neutral attitude towards the acceptance of AML measures. This unpredictable outcome among bank customers of Nepal would be because of the lack of banking skill confidence which would have led to an acceptance of any regimes imposed by the authorities.

The finding shows that there is a significant positive relationship between awareness of AML related factors and acceptance for AML regimes. This means an increase in the level of awareness would increase the level of acceptance for AML policies. This finding is in alignment with the Financial Intelligence Unit - Republic of Mauritius (2006) and Gerstein and Hervieux-Payette (2013). Singh (2009) also had a similar essence. Having an understanding of the nature, scope, and risk of ML, TF and other AML related factors, make the general public more conscious of the policies imposed by the authorities and realize these regimes are for the betterment of all. However, the Organization for Economic Co-operation and Development (2019) argued that awareness is an important factor to suppress ML but among the auditors to detect these illegal assets.

\section{Conclusion}

The purpose of this study is to examine the relationship between awareness of AML factors and acceptance of AML regimes. Based on the descriptive and inferential analysis, the survey was administered on 168 bank customers to collect primary data through a structured questionnaire. The research analyzed the collected data using mean, standard deviation, correlation, and regression analysis. The conclusions drawn after analyzing data along with the recommendations are discussed hereunder.

The bank customers of Nepal have a comparatively higher understanding of ML, TF, AML and KYC than that of AML legislation and investigating agencies, thus, the concerned authorities are advised to undertaking public awareness campaigns in related areas where the awareness lacks. However, they have a similar acceptance attitude towards all three AML regimes. Still, there is ground for increment in the acceptance scale. Thus, awareness resources, the benefit of counter-measures and detailed information regarding AML/CFT policies, role andresponsibilities of customers should be conveyed to customers while opening a bank account is recommended. The study also concludes that an increase 
in the level of awareness of AML related factors would increase the level of acceptance for AML regimes and policies. Increasing the awareness of various aspects related to AML will aid to boost the acceptance level for AML regimes among bank customers, therefore, creating public awareness is the key to impose the AML regimes viably.

Government agencies and policymakers have the idea about the significance of the outcome of this study to formulate positive national policies on a framework that is applicable and sensitive to AML regulations in the banking industry in Nepal. Since the present study is limited to a few independent variables to access the level of awareness of AMLwithonly the bank customers' perspective of AML, it is therefore recommended that further studies take other variables which have prominent impacts on the acceptance of AML regimes and include the bank employees' awareness perspective.

\section{Conflict of Interest}

No conflict of interest is declared while preparing this article.

\section{References}

Ai, T., \& Jun, L. (2009). The international standards of customer due diligence and Chinese practice. Journal of Money Laundering Control, 12(4), 406-416. Retrieved from http://dx.doi.org/10.1108/13685200910996083

Chaikin, D. (2009). How effective are suspicious transaction reporting systems? Journal of Money Laundering Control, 12(3), 238-253. Retrieved from http://dx.doi.org/10.1108/13685200910973628

Demetis, D. S. (2010). Technology and anti-money laundering: A systems theory and risk-based approach. Cheltenham, UK: Edward Elgar Publication Limited.

Demetriades, G. (2016). Is the person who he claims to be?" old fashion due diligence may give the correct answer! Journal of Money Laundering Control, 19(1). Retrieved from http://dx.doi.org/10.1108/JMLC11-2014-0041

European Banking Authority. (2018). Opinion on the use of innovative solutions by credit and financial institutions in the customer due diligence process. doi:JC 201781

Financial Information Unit - Nepal. (2009). Anti-money laundering directives to bank and financial institutions. Kathmandu: Nepal Rastra Bank.

Financial Information Unit - Nepal. (2017/18). Financial information unit annual report. Kathmandu: Nepal Rastra Bank.

Financial Intelligence Unit - Republic of Mauritius . (2006). The risks, extent and trend of money laundering and financing of terrorism in Mauritius. Mauritius: Financial Intelligence Unit.

Gerstein, I. R., \& Hervieux-Payette, C. (2013). Follow the money: Is Canada making progress in combating money laundering and terrorist financing? Not really. Standing Senate Committee on Banking, Trade and Commerce. Retrieved from www.parl.gc.ca

Joyce, B. P. (2002). Dynamics and deficiencies of anti-money laundering efforts in Myanmar. Journal of Money Laundering Control, 6(1), 80- 84.

Kam, B. (2011). Legally, How Young Is Too Young to Open a Savings Account? Retrieved from Consultative Group to Assist the Poor: https://www.cgap.org/blog/legally-how-young-too-young-open-savings-account

Know Your Country. (n. d.). Anti money laundering- Nepal. Retrieved from Know Your Country: https://www. knowyourcountry.com/nepal1111

Mackey, A., \& Gass, S. M. (2005). Second language research. New Jersey: Lawerance Erlbaum Association.

Mukhtar, A. (2018). Money laundering, terror financing and FATF: Implications for Pakistan. Journal of Current Affairs, 3(1), 27-56.

Naheem, M. A. (2018). China's dirty laundry - International organizations posing a risk to China's AML systems. Journal of Money Laundering Control, 21(2), 189-202. Retrieved from https://doi.org/10.1108/JMLC-082015-0032 
Organisation for Economic Co-operation and Development. (2019). Money laundering and terrorist financing awareness and book for tax examiners. Paris: OECD.

Prabhu Bank Limited. (2019). Know your customer (KYC) \& anti-money laundering (AML) policy. Kathmandu: Prabhu Bank Limited.

Republic of Ghana. (2016). National risk assessment on money laundering and terrorist financing. Republic of Ghana.

Singh, V. K. (2009). Controlling money laundering in India - Problems and perspectives. Money and Finance in the Indian Economy. Mumbai: Hidayatullah National Law University.

Subbotina, N. (2009). Challenges that Russian banks face implementing the AML regulations. Journal of Money Laundering Control, 12(1), 19-32. doi:10.1108/13685200910922624

Taber, K. S. (2017). The Use of Cronbach's Alpha When Developing and Reporting Research Instruments in Science Education. Research in Science Education, 48(6), 1273-1296. doi:10.1007/s11165-016-9602-2

United Nations Development Programme Nepal. (2017). Strengthening the rule of law and human rights protection system in Nepal programme (2013-2017). Kathmandu: Government of Nepal.

United Nations Office on Drugs and Crime. (2017). The global programme against money laundering, proceeds of crime and the financing of terrorism. Vienna: United Nations.

Vaithilingam, S., \& Nair, M. (2007). Factors affecting money laundering: Lesson for developing countries. Journal of Money Laundering Control, 10(3),352-366. Retrieved from http://dx.doi.org/10.1108/13685200710763506

Viritha, B., \& Mariappan, V. (2016). Anti-money laundering practices in banks: Customer's awareness and acceptance in india. Journal of Money Laundering Control, 19(3), 278-290. Retrieved from http://dx.doi. org/10.1108/JMLC-03-2015-0009

Viritha, B., Mariappan, V., \& Haq, I. U. (2015). Suspicious transaction reporting: An Indian experience. Journal of Money Laundering Control, 18(1), 2-16. doi:10.1108/JMLC-11-2013-0046 